\title{
Global Soil Moisture Patterns Observed by Space Borne Microwave Radiometers and Scatterometers
}

\author{
R. A. M. de Jeu • W. Wagner - T. R. H. Holmes • A. J. Dolman • \\ N. C. van de Giesen · J. Friesen
}

Received: 15 October 2007/ Accepted: 1 September 2008/Published online: 10 October 2008

(C) The Author(s) 2008. This article is published with open access at Springerlink.com

\begin{abstract}
Within the scope of the upcoming launch of a new water related satellite mission (SMOS) a global evaluation study was performed on two available global soil moisture products. ERS scatterometer surface wetness data was compared to AMSR-E soil moisture data. This study pointed out a strong similarity between both products in sparse to moderate vegetated regions with an average correlation coefficient of 0.83 . Low correlations were found in densely vegetated areas and deserts. The low values in the vegetated regions can be explained by the limited soil moisture retrieval capabilities over dense vegetation covers. Soil emission is attenuated by the canopy and tends to saturate the microwave signal with increasing vegetation density, resulting in a decreased sensor sensitivity to soil moisture variations. It is expected that the new low frequency satellite mission (SMOS) will obtain soil moisture products with a higher quality in these regions. The low correlations in the desert regions are likely due to volume scattering or to the dielectric dynamics within the soil. The volume scattering in dry soils causes a higher backscatter under very dry conditions than under conditions when the sub-surface soil layers are somewhat wet. In addition, at low moisture levels the dielectric constant has a reduced sensitivity in response to changes in the soil moisture content. At a global scale the spatial correspondence of both products is high and both products clearly distinguish similar regions with high seasonal and inter annual variations. Based on the global analyses we concluded that the quality of both products was comparable and in the sparse to
\end{abstract}

R. A. M. de Jeu - T. R. H. Holmes · A. J. Dolman

Department of Hydrology and Geo-Environmental Sciences, Faculty of Earth- and Life Sciences, Vrije Universiteit Amsterdam, Amsterdam, The Netherlands

R. A. M. de Jeu (四)

Vrije Universiteit Amsterdam, FALW, De Boelelaan 1085, 1081 HV Amsterdam, The Netherlands e-mail: richard.de.jeu@falw.vu.nl

W. Wagner

Institute of Photogrammetry and Remote Sensing, Vienna University of Technology, Vienna, Austria

N. C. van de Giesen · J. Friesen

Faculty of Civil Engineering and Geosciences, Water Resources Section, Technical University Delft, Delft, The Netherlands 
moderate vegetated regions both products may be beneficial for large scale validation of SMOS soil moisture. Some limitations of the studied products are different, pointing to significant potential for combining both products into one superior soil moisture data set.

Keywords Hydrology · Global - Soil moisture - Remote sensing · Satellites · SMOS

\section{Introduction}

Soil moisture is an important state variable in land surface hydrology and has a dominant influence on physical processes. It is a variable that has always been required in many disciplinary and cross-cutting scientific and operational applications (e.g. ecology, biogeochemical cycles, climate monitoring, flood forecasting, etc.) (Jackson et al. 1999). Unfortunately, accurate estimates of surface soil moisture are often difficult to make, especially at larger spatial scale. The main reason is that it is a very difficult variable to measure, not at a point in time, but on a consistent and spatially comprehensive basis (Leese et al. 2001).

Satellite remote sensing can be a powerful tool in fulfilling those needs because it can monitor environmental processes in both spatial and temporal terms. Since the 1960s, satellites have provided data for water resources management. Most importantly, visible and infrared imaging sensors have been used for observing land surface parameters such as snow cover, surface water areas, land use and surface temperature (Schmugge 1985). A major drawback of these instruments is their dependence on atmospheric conditions. The occurrence of clouds, water vapor and aerosols can easily disturb the signals, resulting in limited land surface information. Also, with the exception of thermal infrared sensors, these techniques depend on the sun as a source of illumination of the land surface and cannot provide data during night time and low sun elevation. On the other hand, remote sensing instruments working in the microwave range of the electromagnetic spectrum can be operated day and night and are less affected by atmospheric conditions. This has prompted much research and development in the field of microwave remote sensing.

In microwave remote sensing one distinguishes active and passive techniques. While passive microwave radiometers record naturally emitted radiation, active microwave sensors transmit electromagnetic waves and record the backscattered radiation. The latter are often referred to as radar which stands for radio detection and ranging. Because scattering and emission phenomena are closely related (Schanda 1986), the development of passive and active microwave remote sensing techniques went hand in hand. The first space-borne earth-observation radiometer was launched in 1968 on the Russian satellite Comos 243, followed ten years later by the first spaceborne radar satellite Seasat that was built and operated by NASA (Ulaby et al. 1981). Since then numerous satellites carrying microwave radiometers and/or radar instruments have been launched.

The potential of microwave sensors for measuring soil moisture has been recognized early (Eagleman and Ulaby 1975). The theoretical basis for measuring soil moisture at microwave frequencies lies in the large contrast between the dielectric properties of liquid water and dry soil material. The large dielectric constant of water is the result of the water molecule's alignment of its permanent electric dipole in response to an applied electromagnetic field. Therefore, when water is added to the soil matrix, the effective dielectric constant of the soil increases strongly (Hipp 1974). Since the emission and scattering properties of the soil are strongly influenced by the soil dielectric constant, both active and 
passive microwave measurements are highly sensitive to soil moisture (Ulaby 1974; Schmugge et al. 1986).

For retrieving soil moisture it is necessary to develop models that are capable of accounting for vegetation and surface roughness effects on the microwave signal. In 1975 Wilheit developed one of the first radiative transfer models that described the physics of microwave radiation in the soil. This important step in microwave research started a series of papers on the possibilities to retrieve soil moisture in both the active and passive microwave domain. In the passive domain Njoku and Kong (1977) used a simple regression technique on multi frequency microwave observations in combination with a given surface temperature to obtain soil moisture from a controlled bare soil site. In time, these models started to become more complex with the addition of surface roughness models (Choudhury et al. 1979; Wang and Choudhury 1981; Wigneron et al. 2001) canopy layers (Kirdiashev et al. 1979; Mo et al. 1982), atmosphere layers (Pellarin et al. 2003; Liebe 2004), snow layers (Pulliainen et al. 1999) and better dielectric mixing models (Wang and Schmugge 1980; Dobson et al. 1985; Peplenski et al. 1995; Mironov et al. 2004). In the active domain, important steps were the development of bare soil backscatter models (Fung et al. 1992; Oh et al. 1992) and vegetation scattering models (Attema and Ulaby 1978; Fung 1979).

Methodological problems, lack of validation data and limitations in computing have frequently delayed the research progress to retrieve soil moisture from space observations (Wagner et al. 2007a). But now, more than 20 years later, research in these fields has resulted in several global and continental scale soil moisture datasets (e.g. Wagner et al. 2003; Njoku et al. 2003; Owe et al. 2008). Also, the launch of the soil moisture and ocean salinity (SMOS) satellite is anticipated (Kerr et al. 2001). SMOS uses a synthetic aperture radiometer operated in L-band and is the first satellite dedicated to measuring soil moisture over land. In preparation for SMOS, research in the passive microwave domain has accelerated and supporting field studies have resulted in various new insights. For example, microwave emission from the soil surface can now be described with more physically based soil transition models (Schneeberger et al. 2004) in stead of the existing empirical descriptions (i.e. Choudhury et al. 1979; Wang and Choudhury 1981). At field sites, the effect of the vegetation cover on the microwave observations has been studied intensively. Saleh et al. (2006) discovered a strong contribution of litter and wet canopy on the microwave emission and Schwank et al. (2005) demonstrated the effects of vegetation structure change by studying microwave observations of clover grass prior and after a hail storm. However, these studies are all based on L-band microwave observations at field sites and the validity of these findings at global scale has yet to be shown.

For a better understanding of the capabilities of existing active and passive microwave instruments and in preparation for SMOS, this paper compares two promising global soil moisture data sets. The first soil moisture dataset was obtained from a low resolution $(50 \mathrm{~km})$ scatterometer originally designed for measuring winds over the oceans. The scatterometer product has been developed by researchers of the Vienna University of Technology and is based on backscatter data acquired by the C-band $(5.3 \mathrm{GHz})$ scatterometer on board of the European satellites ERS-1 and ERS-2 (Wagner et al. 1999b). This product has already been used in numerous research projects (e.g. Dirmeyer et al. 2004; Pellarin et al. 2006; Parajka et al. 2006; Crow and Zhan 2007). The second soil moisture data set has been developed jointly by researchers of NASA Goddard Space Flight Center and the Vrije Universiteit Amsterdam (Owe et al. 2008). It uses low frequency AMSR-E microwave brightness temperatures to obtain soil moisture. Both global products have recently been tested in a series of validation studies. Table 1 gives a summary of these 


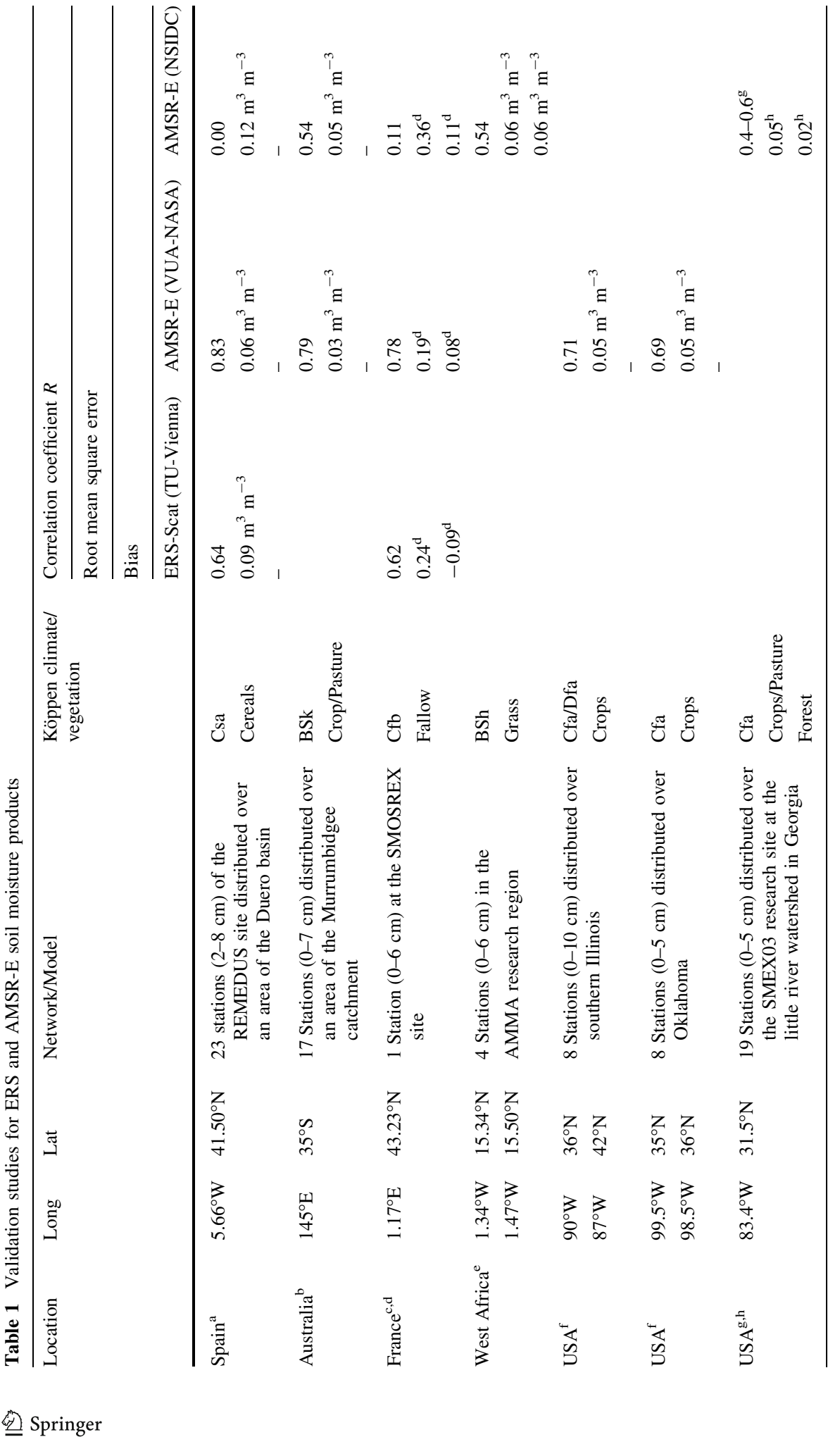




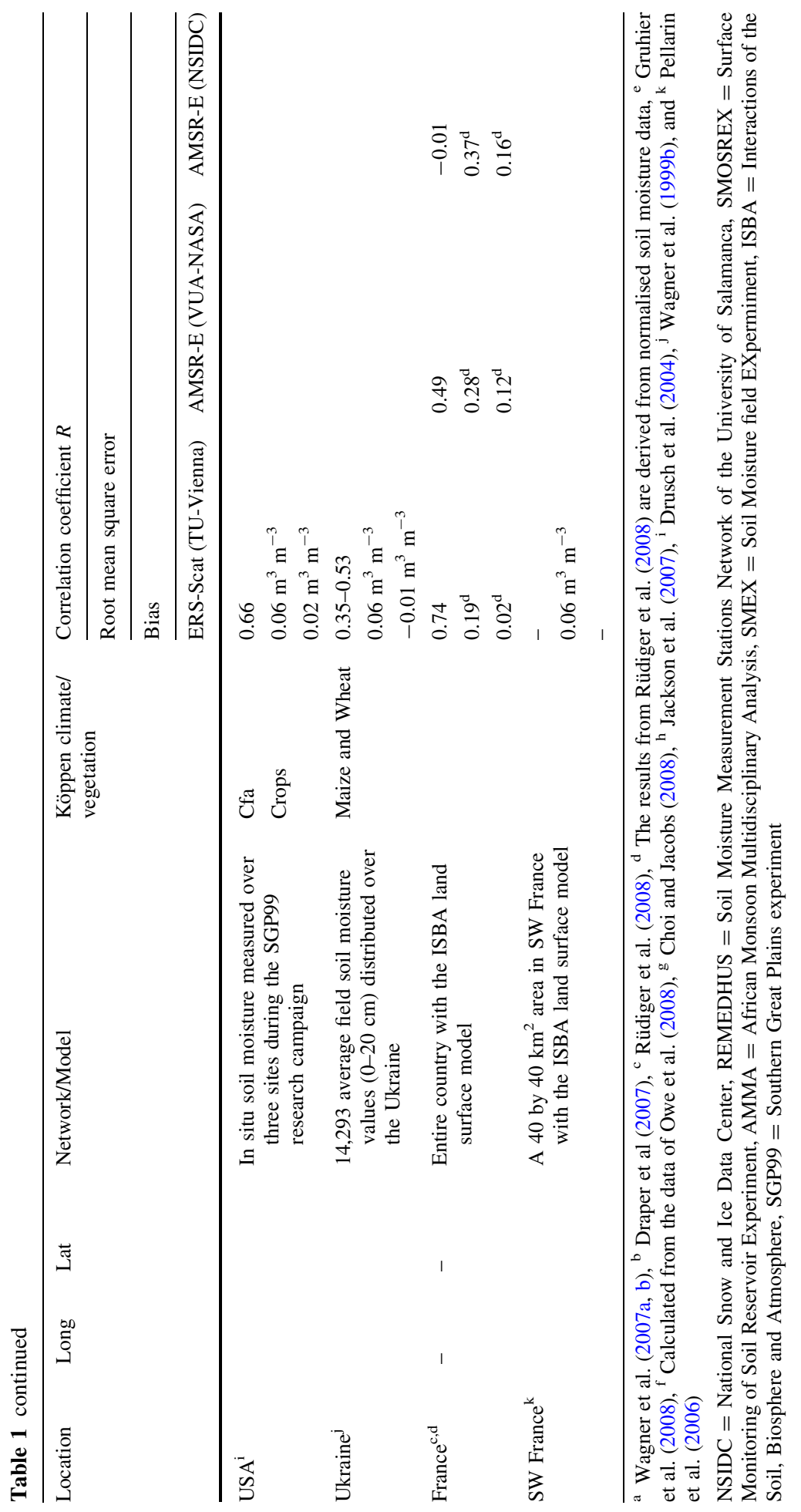


validation activities. The table also includes the validation activities on the official AMSRE daily Level 3 surface soil moisture product of the National Snow and Ice Data Center (NSIDC; Njoku et al. 2003).

This table does not cover all vegetation types and climate regimes, but it clearly shows a poor performance of the AMSR-E (NSIDC) product on both field and model validations. AMSR-E (VUA-NASA) has the highest correlations with field observations and the ERS product shows high correlations with a land surface model. Consequently, we chose to focus our analysis on the two most promising products: ERS and AMSR-E (VUA-NASA).

The two products are based on different sensor technologies and retrieval approaches. Given the uncertainties pertaining to both products, a direct comparison does not allow determining the exact quality of either one of the two products. Nevertheless, in regions where both products exhibit the same statistics (in terms of correlation, seasonal- and interannual variation), it is very likely these statistics represent the actual soil moisture characteristics. This is because it is extremely unlikely that the same systematic errors are present in both independent data sets, given the very different sensors and retrieval approaches. Only if the error is directly related to the dielectric properties of the land surface (e.g. salt plains), the statistics of both products would be compromised.

This paper describes briefly the theoretical background of each product followed by a temporal and spatial analysis. The weaknesses and strengths of each product are discussed, which will be valuable information for future microwave missions.

\section{Global Soil Moisture Products}

\subsection{AMSR-E Soil Moisture}

Satellite observations from the Advanced Microwave Scanning Radiometer (AMSR-E) on board of the AQUA satellite are used for soil moisture mapping. The instrument measures the microwave radiation emitted by the Earth's surface in vertical and horizontal polarization, expressed in terms of brightness temperature. AMSR-E provides the global passive microwave observations at 6 different frequencies, including $6.9 \mathrm{GHz}$ (C-band), $10.7 \mathrm{GHz}$ (X-band) and the $36.5 \mathrm{GHz}$ (Ka-band). The spatial resolution of the footprint measurements is $56 \mathrm{~km}$ at C-band, $38 \mathrm{~km}$ at X-band and $12 \mathrm{~km}$ at Ka-band. AMSR-E scans the Earth's surface in an ascending $(1: 30 \mathrm{pm})$ and descending $(1: 30 \mathrm{am})$ mode. In this study we used the observations from the ascending mode.

Level 2A globally swatted brightness temperatures are obtained from NSIDC and the retrieved soil moisture is resampled to a 0.25 degree grid in order to become spatially consistent. AMSR-E was launched in May 2002 and is currently still active. Daily Earth coverage is nearly $100 \%$ above and below 45 degrees North and South latitude, while midlatitudes experience about $80 \%$ coverage (Ashcroft and Wentz 2003; NSIDC 2006).

The brightness temperatures are converted to soil moisture values with the Land Parameter Retrieval Model (LPRM; Owe et al. 2008). The LPRM is based on a microwave radiative transfer model that links surface geophysical variables (i.e. soil moisture, vegetation water content, and soil/canopy temperature) to the observed brightness temperatures.

The thermal radiation in the microwave region is emitted by all natural surfaces, and is a function of both the land surface and the atmosphere. The contribution of the atmosphere to the observed brightness temperature may be expressed as 


$$
T_{B p}=T_{u}+\exp \left(-\tau_{a}\right) T_{b p}+r_{p} T_{d}
$$

where $T_{u}$ and $T_{d}$ are the upwelling and downwelling atmospheric emissions respectively, $\tau_{a}$ is the atmospheric opacity, $r_{p}$ is the surface reflectivity, and $T_{b p}$ is the surface brightness temperature. The subscript $p$ denotes either horizontal $(\mathrm{H})$ or vertical $(\mathrm{V})$ polarization. The surface brightness temperature is a function of the physical temperature of the radiating body and its emissivity, according to

$$
T_{b p} \cong e_{s p} T_{s}
$$

where $T_{s}$ is the thermodynamic temperature of the emitting layer, and $e_{s p}$ is the smoothsurface emissivity. The emissivity may be further defined as

$$
e_{s p}=\left(1-R_{s p}\right)
$$

where $R_{\mathrm{s}}$ is the smooth-surface reflectivity. The contribution of roughness on the microwave emission is significant and can be described by different surface roughness models. The LPRM uses the roughness model of Wang and Choudhury (1981). The emissivity is directly related to the dielectric constant of the soil and this relation can be described with the Fresnel relations.

As already mentioned earlier soil moisture retrieval from microwave measurements is made possible due to the large contrast between the dielectric constants of dry soil $(\sim 4)$ and water $(\sim 80)$. This contrast results in a broad range in the dielectric properties of soilwater mixtures (4-40), and is the primary influence on the natural microwave emission from the soil (Schmugge et al. 1986). The dielectric constant is defined as a complex number, where the real part determines the propagation characteristics of the energy as it passes upward through the soil, and the imaginary part determines the energy losses. In a heterogeneous medium such as soil, the complex dielectric constant is a combination of the individual dielectric constants of its constituent parts, and includes air, water, rock, etc. Other factors which will influence the dielectric constant are temperature, salinity, soil texture, and wavelength. The dielectric constant is a difficult quantity to measure on a routine basis outside the laboratory, and values are generally derived from dielectric mixing models that uses an estimation of the ratio rock/water/air based on the given soil properties to calculate the dielectric constant (Dobson et al. 1985; Mironov et al. 2004; Wang and Schmugge 1980). In 1998 Owe and Van de Griend compared the Dobson and the Wang-Schmugge model and they concluded that the Wang-Schmugge model had better agreement with the laboratory dielectric constant measurements. Consequently, the LPRM uses the Wang-Schmugge model to describe the dielectric properties of the soil.

Figure 1a demonstrates the theoretical Fresnel relationship between the soil dielectric properties and smooth surface emissivities at horizontal $(\mathrm{H})$ and vertical $(\mathrm{V})$ polarization for the AMSR-E incidence angle of 55 degrees. To simplify the graph, the complex dielectric constant of the soil moisture water mixture is expressed as an absolute value ( $|\varepsilon|)$. While the absolute magnitude of the soil emissivity is somewhat lower at horizontal polarization, the sensitivity to changes in soil dielectrics and therefore in soil moisture is significantly greater than at vertical polarization (See Fig. 1a). This subsequently forms the basis of several approaches to use horizontal polarized brightness temperatures for soil moisture retrieval (e.g. Njoku and Li 1999; Owe et al. 2001).

In addition, the relationship between soil dielectric constant and soil moisture is expressed in Fig. 1b. This relationship is derived from the Wang-Schmugge model and describes the relationship for a typical sand, loam and clay soil. The relationship is almost 

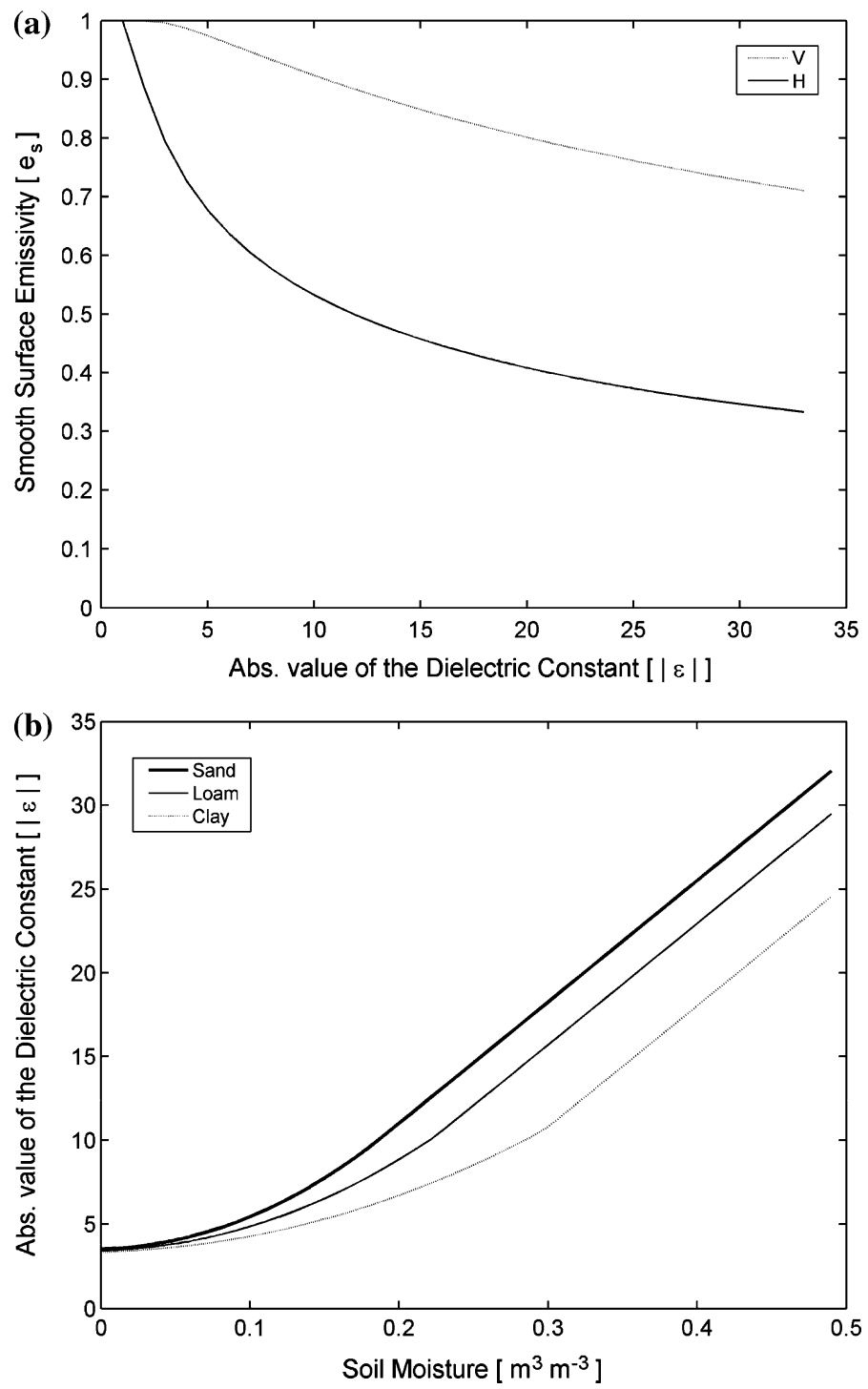

Fig. 1 (a) Comparison of smooth surface emissivity and the soil dielectric constant according to the Fresnel relations with an incidence angle of 55 degrees. (b) Comparison of the soil dielectric constant and soil moisture for typical sand, loam and clay soils

linear except at low moisture contents (See Fig. 1b). This non-linearity at low moisture contents is due to the strong bonds which develop between the surfaces of the soil particles and the thin films of water which surround them. These bonds are so strong at low moisture levels, that the free rotation of the water molecules is impeded. This is often referred as the bound water phase. Therefore, in a relatively dry soil, the water is tightly bound and contributes little to the dielectric constant of the soil water mixture. As more water is added, the molecules are further from the particle surface and are able to rotate more freely. This is often referred as the free water phase. The subsequent influence of the free 
water on the soil dielectric constant therefore also increases. Soils with an high clay content will generally have a lower dielectric constant than coarse sandy soils at the same moisture content, since more water is being held in the bound water phase (De Jeu 2003).

Vegetation affects the microwave emission as observed from above the canopy in two ways. First, vegetation will absorb or scatter the radiation emanating from the soil. Secondly, the vegetation will also emit its own radiation. These two effects tend to counteract each other. The observable soil emission will decrease with increased vegetation, while emission from the vegetation will increase. Under a sufficiently dense canopy, the emitted soil radiation will become totally masked, and the observed emissivity will be due largely to the vegetation. The magnitude of the absorption depends upon the wavelength and the water content of the vegetation. The most frequently used wavelengths for soil moisture sensing are in the L, C- and X-bandwidths $(\sim 1.4, \sim 6$ and $\sim 10 \mathrm{GHz}$ respectively), with L-band sensors having greater penetration of vegetation. While observations at all frequencies are subject to scattering and absorption and require some correction if the data are to be used for soil moisture retrieval, shorter wave bands are more susceptible to vegetation influences. A variety of models have been developed to account for the effects of vegetation on the observed microwave signal, and range from empirical linear models (Jackson et al. 1982; Ahmed 1995), to more physically-based radiative transfer treatments (Meesters et al. 2005; Mo et al. 1982; Njoku and Li 1999; Wigneron et al. 1995; Wegmuller et al. 1995).

The radiation from the land surface as observed from above the canopy may be expressed in terms of the radiative brightness temperature, $T_{b p}$, and is given as a simple radiative transfer equation (Mo et al. 1982),

$$
T_{b p}=T_{S} e_{r p} \Gamma_{p}+\left(1-\omega_{p}\right) T_{C}\left(1-\Gamma_{p}\right)+\left(1-e_{r p}\right)\left(1-\omega_{p}\right) T_{C}\left(1-\Gamma_{p}\right) \Gamma_{p}
$$

where $T_{S}$ and $T_{C}$ are the thermodynamic temperatures of the soil and the canopy respectively, $\omega$ is the single scattering albedo, and $\Gamma$ is the transmissivity. The first term of the above equation defines the radiation from the soil as attenuated by the overlying vegetation. The second term accounts for the upward radiation directly from the vegetation, while the third term defines the downward radiation from the vegetation, reflected upward by the soil and again attenuated by the canopy. The transmissivity is further defined in terms of the optical depth, $\tau$, and incidence angle, $u$, such that

$$
\Gamma=\exp (-\tau / \cos u)
$$

The optical depth is strongly related to the canopy density, and for frequencies less than $10 \mathrm{GHz}$, it can be expressed as a linear function of vegetation water content (Jackson et al. 1982). It was shown that at C-band, the above-canopy signal becomes totally saturated at an optical depth of about $1.5(\omega=0.06)$ in the horizontal channel, although for practical purposes, the sensitivity is already quite low above 0.75 (Owe et al. 2001).

The single scattering albedo describes the scattering of the soil emissivity by the vegetation, and is a function of plant geometry. The scattering albedo may be calculated theoretically (Wegmuller et al. 1995), however, experimental data for this parameter are limited, and values for selected crops were found to vary from 0.04 to about 0.13 (Mo et al. 1982; Owe et al. 2001). Few values are found for natural vegetation. A 3-year time series of the scattering albedo at both $6.6 \mathrm{GHz}$ and $37 \mathrm{GHz}$ was calculated for an African savanna region (Van de Griend and Owe 1994). The scattering albedo exhibited considerable variability during the period, although no relationship with vegetation biomass or other seasonal indicators was observed. 
Table 2 Model configuration of the land parameter retrieval model (LPRM)

\begin{tabular}{ll}
\hline Components & Module \\
\hline Dielectric Mixing Model & Wang and Schmugge (1980) \\
Reflectivity Model & Fresnel Law \\
Roughness Model & Wang and Choudhury (1981) \\
Temperature Model & De Jeu and Owe (2003) \\
Canopy Layer & Mo et al. (1982) \\
Vegetation Optical Depth Model & Meesters et al. (2005) \\
Atmosphere & Pellarin et al. (2003) \\
\hline
\end{tabular}

While there is some experimental evidence indicating possible polarization dependence of both the optical depth and the scattering albedo, these differences have been observed mainly during field experiments and over vegetation elements that exhibit some uniform orientation such as vertical stalks in tall grasses, grains, and maize (Wigneron et al. 1995; Wegmuller et al. 1995; Kirdiashev et al. 1979). However, the canopy and stem structure for most crops and naturally occurring vegetation are randomly oriented. Furthermore, the affects of any systematic orientation exhibited by vegetation elements would most likely be minimized at satellite scales (Owe et al. 2001)

Table 2 summarizes the different modules used by the LPRM. The model uses either Cband or X-band for soil moisture retrieval. For this study four years (i.e. 2003-2006) of descending C- and X-band soil moisture are used. The soil moisture products from the LPRM represent soil moisture of the first centimeters and are expressed in volumetric values. The product is validated at different regions of the world and compares well to field observations (see Table 1).

In 2003 De Jeu performed an error propagation analysis on the LPRM for Nimbus 7SMMR C-band brightness temperature observations over five selected sites (i.e. three agricultural sites in the U.S. and two semi arid sites in respectively Mongolia, and Turkmenistan). The resulting standard deviation of the soil moisture varies between $0.03 \mathrm{~m}^{3} \mathrm{~m}^{-3}$ and $0.13 \mathrm{~m}^{3} \mathrm{~m}^{-3}$, with an average value of $0.05 \pm 0.02 \mathrm{~m}^{3} \mathrm{~m}^{-3}$ and is seen to be related to the vegetation optical depth (Fig. 2). The illustration reveals an increased uncertainty in the soil moisture retrievals as the vegetation density increases. This is consistent with theoretical predictions, which indicate that as the observed soil emissivity decreases with an increase in vegetation biomass, the soil moisture information contained in the microwave signal decreases.

The same figure also illustrates noticeably higher standard deviations at relatively low optical depths. This phenomenon appears to be most pronounced within the lower range of soil moisture values $\left(0.0\right.$ and $\left.0.1 \mathrm{~m}^{3} \mathrm{~m}^{-3}\right)$. For example, within this soil moisture range the standard deviations are predominantly between 0.04 and $0.13 \mathrm{~m}^{3} \mathrm{~m}^{-3}$. This may be due to the reduced sensitivity in the dielectric constant in response to changes in the moisture content at low moisture levels. Within this range, changes in soil moisture have only a minimal effect on the soil dielectric.

A data mask was developed on the AMSR-E data products to eliminate those data cells where data values were either meaningless due to frozen soil conditions, snow cover or excessive vegetation, or were unreliable because the residual between observed and modelled brightness temperature exceeds $0.25 \mathrm{~K}$. Pixels with snow and frozen soils were detected with a simple surface temperature algorithm (De Jeu and Owe 2003). Soil emission is attenuated by the canopy and tends to saturate the microwave signal with 


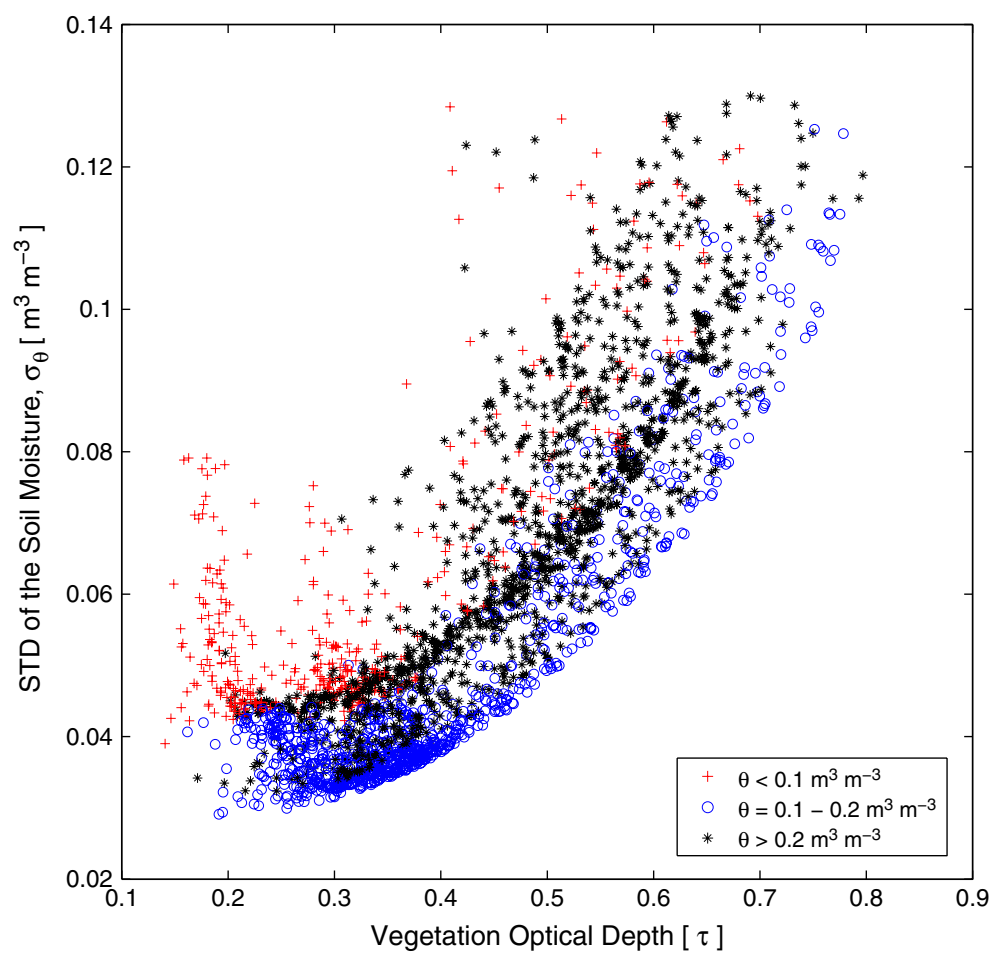

Fig. 2 The standard deviation of the retrieved soil moisture as related to the vegetation optical depth. The results are based on an error propagation analysis on Nimbus-SMMR C-band brightness temperatures (taken from De Jeu 2003). Note the different relations for different moisture regimes

increasing vegetation density, resulting in decreased sensor sensitivity to soil moisture variations (e.g. Fig. 2). For this reason pixels with a vegetation optical depth exceeding 0.8 were removed.

The effect of vegetation density on the decrease of sensitivity to soil moisture variations is inversely proportional to the wavelength and therefore higher at X-band than at C-band.

\subsection{ERS Soil Moisture}

The second soil moisture product is derived from C-band $(5.3 \mathrm{GHz})$ backscatter measurements acquired by the scatterometer on board of the European remote sensing satellites ERS-1 and ERS-2. The ERS scatterometer has been operational for monitoring wind speed and direction over the oceans. It is configured as a real aperture radar providing three radar images of the Earth's surface with a spatial resolution of $50 \mathrm{~km}$ and a swath width of $500 \mathrm{~km}$ (Lecomte 1998). The three images are acquired by three different antennas that sequentially transmit micro-second long pulses towards the Earth's surface from different viewing directions. The antenna look directions are perpendicular to the ERS ground track, $45^{\circ}$ forwards and $45^{\circ}$ backwards looking. After reception of the return echoes, noncoherent power detection is performed. The raw measurements are finally calibrated to obtain images of the backscattering coefficient $\sigma^{0}$. 
Due to the mono-static measurement configuration and the coherent nature of the radar signal, scatterometer measurements are very sensitive to the roughness of the illuminated surface at scales comparable to the wavelengths. Over the oceans, wind near the water surface causes small ripples to form which consequently enhance radar backscatter (Young and Moore 1977). This increase in backscatter is modulated by the orientation of the antennas relative to the wind direction, whereas the backscattering coefficient exhibits maxima in the upwind and downwind directions and minima in the cross-wind directions (McLaughlin et al. 1991). Therefore it is possible in a relatively direct manner to estimate the speed and direction of ocean winds from the three backscatter measurements of the ERS scatterometer. Also over land and ice, the backscattering coefficient is very sensitive to the roughness of the surface. However, contrary to scatterometer observations over sea, azimuthal modulations of the backscattering signal are generally weak. The exceptions are areas where wind shapes the surface microrelief. Remy et al. (1992) discovered that over Antarctica the minimum values of the backscatter coefficient are always observed in the direction of katabatic winds. They explained this by the presence of sastrugi, which are streamlined features formed on the snow surface in the wind direction. Over land, areas of strong azimuthal anisotrophy can be found in sand deserts, where the prevailing winds form the shape and microrelief of the sand dunes (Stephen and Long 2005; Bartalis et al. 2006).

Besides roughness, the strength of the echoes backscattered from rough surfaces depends on how much of the incoming energy is absorbed by the surface material and how much is reradiated by the induced conduction and displacement currents (Ulaby et al. 1982). In electromagnetic theory these material properties are described on a macroscopic level by the dielectric constant which is a number relating the ability of a material to carry alternating current to the ability of vacuum to carry alternating current. In general, one finds backscatter to increase with an increasing dielectric constant of the surface material regardless of the roughness characteristics of the surface. In ocean wind retrieval with $\mathrm{C}$ band scatterometers, the dielectric constant is not important because the dielectric constant of the ocean water is fairly constant, only changing somewhat with water temperature and ocean salinity (Schanda 1986). However, over bare or sparsely vegetated land surfaces much of the variability of C-band backscatter measurements is the result of soil moisture induced changes of the soil dielectric constant. This is the basis for using C-band scatterometers also for the retrieval of soil moisture over land.

The soil moisture data sets used in this study has been derived using the retrieval method proposed by Wagner et al. (1999a, 2003). Because of the current limitations of bare soil backscatter models (Walker et al. 2004), the method rests upon a change detection approach that tracks relative soil moisture changes rather than trying to estimate absolute soil moisture values. Dry and wet reference conditions are identified based on multi-year backscatter time series. In this way, the method indirectly accounts for spatial patterns of surface roughness and land cover. For quantifying the effect of seasonal vegetation change, the method makes use of the fact that the three scatterometer antennas look at the surface from different incidence angles (Wagner et al. 1999b). Given that vegetation influences backscatter at different incidence angles differently, temporal changes in backscatter due to soil moisture and seasonal vegetation change can be modelled.

As a result, time series of the topsoil moisture content $\mathrm{ms}(<5 \mathrm{~cm})$ are obtained. It is a relative quantity ranging between 0 and 1 (respectively, $0-100 \%$ ), scaled between zero soil moisture and saturation.

This data set is available since 2002 from the website http://www.ipf.tuwien.ac.at/radar and has been used in various studies (See Table 1). For example, Pellarin et al. (2006) 
validated the precision of this data set over a half-degree region in Southwestern France. Based on a high resolution soil moisture simulation $\left(1 \mathrm{~km}^{2}\right)$ validated at the local scale, the root mean square error of the ERS soil moisture data set was estimated to be $0.06 \mathrm{~m}^{3} \mathrm{~m}^{-3}$. Using a novel data assimilation-based approach for the continental-scale evaluation of remotely sensed surface soil moisture Crow et al. (2007) found this product over contiguous United States to be roughly on a par with the AMSR-E soil moisture product of NASA (Njoku et al. 2003) - perhaps slightly better in heavily vegetated areas. However, the results of Crow et al. (2007) suggest that it performs less well compared to an unpublished soil moisture product derived by T. J. Jackson and X. Zhan of the U.S. Department of Agriculture (USDA) Hydrology and Remote Sensing Laboratory based on AMSR-E and MODIS data.

The ERS soil moisture data are available since 1991 up to the present, although data coverage is variable in space and time due to conflicting operations of the Synthetic Aperture Radar (SAR) on board of ERS-1/2. Also, after the failure of the last gyroscope of ERS-2 in January 2001, the distribution of scatterometer data was temporarily discontinued because no software was initially available to calibrate the backscatter data (Crapolicchio and Lecomte 2005). A further event that had a strong impact on the Scatterometer mission occurred at the end of June 2003, when the two on-board tape recorders became unusable. That fact caused the loss of the global Earth coverage because the data could no longer be recorded on-board. In response to this problem, ESA started building up a network of ground receiving stations which provided coverage of Europe, North Africa, North America and some other regions.

\section{Evaluation}

The scatterometer-derived surface wetness is compared with the AMSR-E C-band surface soil moisture for the overlapping year 2006 over two regions with a sufficient ERS observation density; North America and Europe/North Africa. Figure 3 gives an overview of the average soil moisture distribution for 2006 of both the ERS and AMSR-E products for these regions. While the scatterometer data is available on an irregular grid with $28-\mathrm{km}$ pixel spacing, both the $\mathrm{C}$-band and $\mathrm{X}$-band radiometer data are given on a regular 0.25 degree grid.

In general the soil moisture patterns are similar over the major part of the land surface with dry regions in the Midwest of the US, Sahara, and the Arabian Peninsula. Wet regions are detected in North eastern part of the US and Canada, and Northern Europe. In the U.S. clear differences between ERS and AMSR-E can be found along the western part of the lower basin of the Mississippi and in Northern Mexico along the border with the US. The ERS soil moisture values in the lower basin of the Mississippi are low, which is highly unusual because this is a heavily vegetated region with a lot of water bodies. The apparent detection of a wet region in northern Mexico of ERS is also odd. This phenomenon has also been observed in other desert regions. We speculate that this might be caused by volume scattering in dry soil or by the reduced sensitivity of the dielectric constant at these low soil moisture levels as indicated in Fig. 2. As Schanda (1987) discusses total backscatter from rough soil surface is due to scattering at the air-soil boundary layer and volume scattering from sub-surface soil layers. Because the penetration depth of microwaves rapidly decreases with increasing soil wetness, the volume scattering contribution can in general be neglected. However, for very dry soil conditions, this may not necessarily be a valid assumption. 
(a)

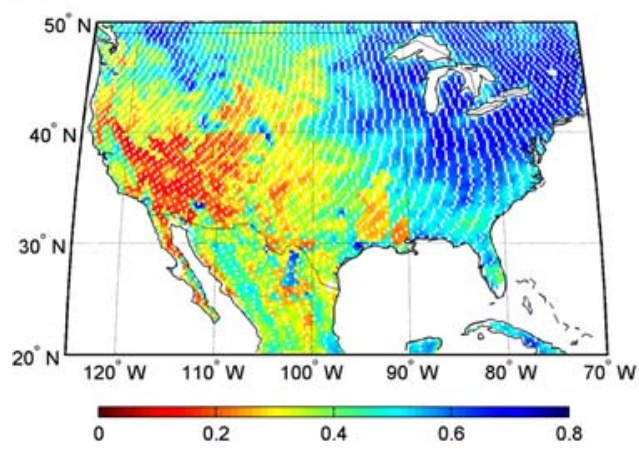

(c)

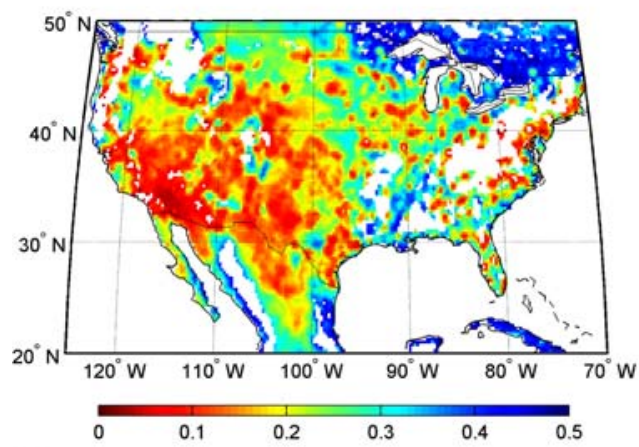

(e)

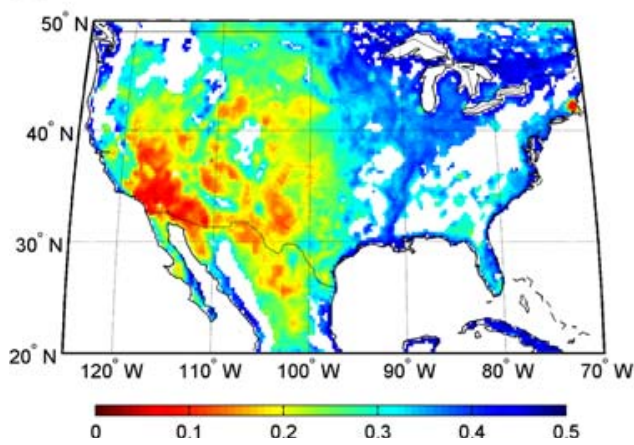

(b)

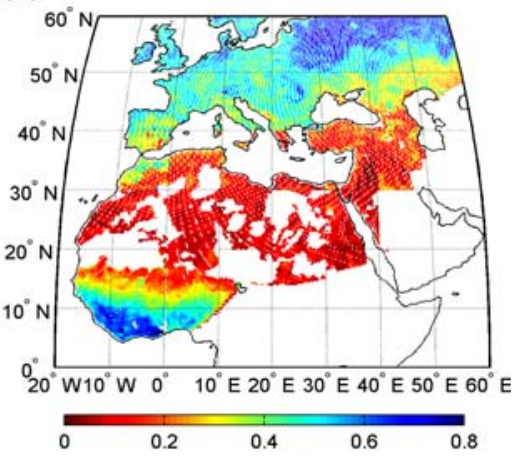

(d)

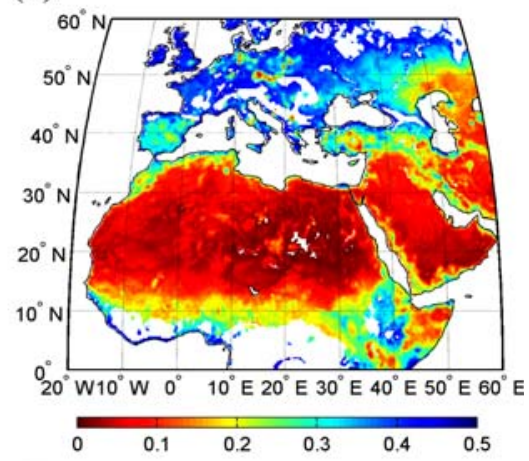

(f)

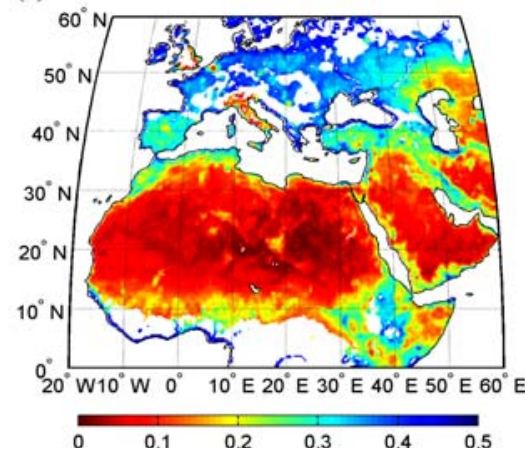

Fig. 3 Average soil moisture of 2006 for the United States and a large part of Europe and Northern Africa. (a) and (b) are derived from ERS data, (c) and (d) from C-band AMSR-E data and (e) and (f) from X-band AMSR-E. ERS soil moisture is expressed as a relative quantity ranging between 0 and 1 and scaled between zero soil moisture and saturation. The units of AMSR-E soil moisture are volumetric and given in $\mathrm{m}^{3} \mathrm{~m}^{-3}$

Figure 3c clearly demonstrates the effect of Radio Frequency Interference (RFI) in the C-band soil moisture product over the Eastern part of the US. Compare to the X-band soil moisture map of the US, the C-band has a lot of small areas with unusually dry sites in the eastern part of the US. These dry areas are caused by artificial disturbances and are most likely caused by active radar instruments on the ground. These instruments can emit electromagnetic radiation in $\mathrm{C}$ and $\mathrm{X}$-band and can therefore disturb the measurement of 
the natural microwave emission of the surface. These RFI's always result in unusually dry values in the AMSR-E soil moisture products. At C band RFI occurs mostly at or near major cities or airports in the US, Middle East and Japan (Njoku et al. 2005). At X-band RFI is more a problem in Europe, with some significant disturbances in England (UK), Belgium, and a large part of Italy. RFI is a well known problem in AMSR-E data (Li et al. 2004) and there is currently research in progress at NASA Jet Propulsion Laboratory to develop RFI filters (Njoku et al. 2005). Given a map of well known RFI regions the most appropriate band can be selected.

In addition, the follow-up mission for AQUA-AMSR-E, the Global Change Observation Mission for the observation of the Water cycle (GCOM-W) will carry a similar radiometer with an addition channel in C-band (i.e. the $7.3 \mathrm{GHz}$ channel) to correct for RFI (Imaoka et al. 2006).

In Fig. 4 the correlation coefficient $R$ values between ERS and AMSR-E soil moisture of 2006 can be seen for the US and Europe/Northern Africa. In general, $R$ is positive over the major part of the land surfaces with maximum values even beyond 0.9 in the Sahel region and North of the Black and Caspian Sea. The comparison of both C-band and $\mathrm{X}$-band with ERS show almost exact similar patterns. Low and negative values can be found in the deserts and the more densely vegetated regions. This is confirmed by Fig. 5a,

(a)

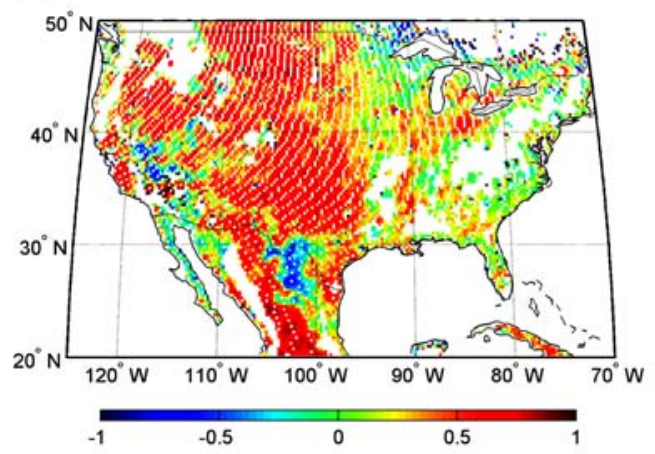

(c)

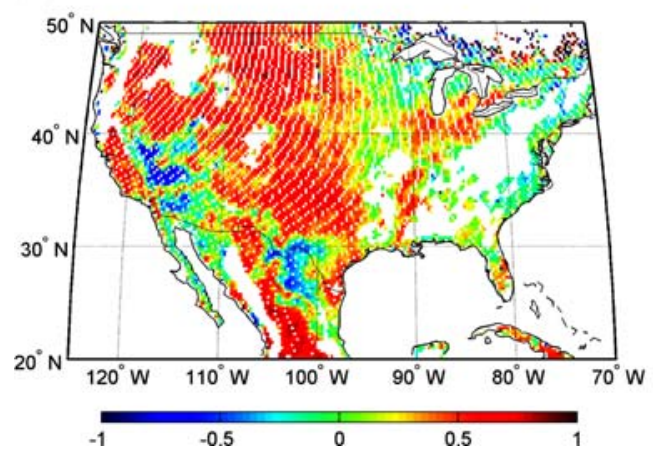

(b)

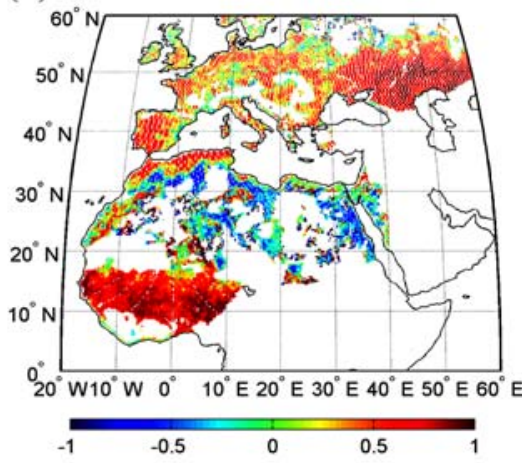

(d)

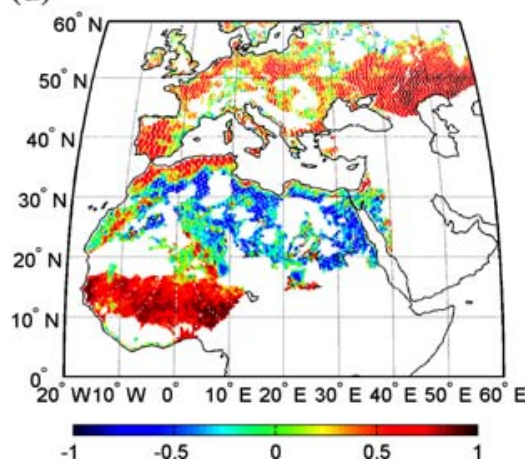

Fig. 4 Correlation coefficient maps between ERS and AMSR-E soil moisture of 2006 for the United States and a large part of Europe and Northern Africa. (a) and (b) show the correlation coefficient between ERS and AMSR-E C-band soil moisture; (c) and (d) the correlation coefficient between ERS and AMSR-E $\mathrm{X}$-band 

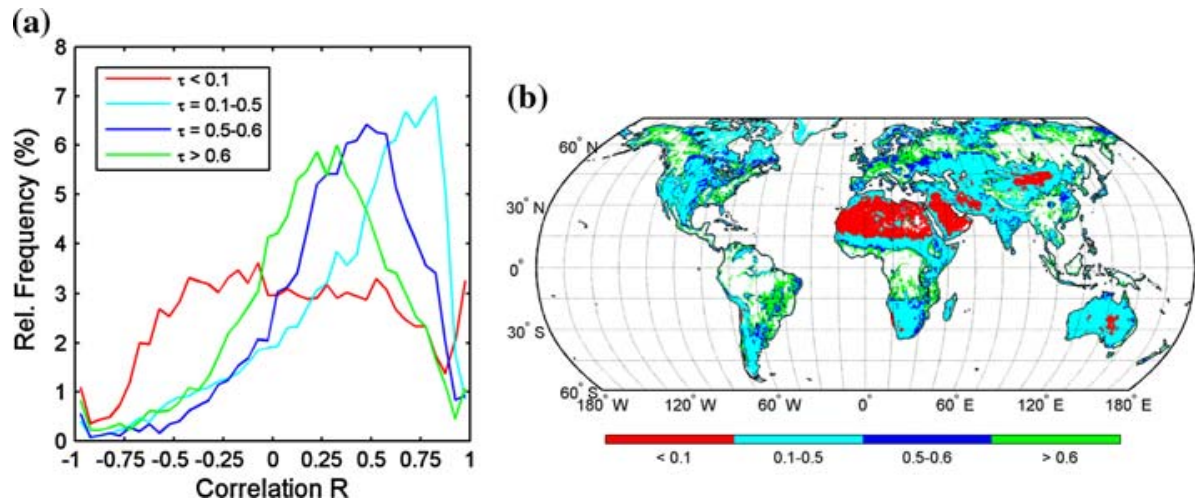

Fig. 5 (a) Histogram of correlation coefficient $R$ between ERS and AMSR-E surface soil moisture for 2006 for four classes representing different vegetation densities; (b) shows the spatial distribution of these different vegetation densities at a global scale

which shows histograms of $R$ between ERS and AMSR-E C band stratified according to vegetation density. The vegetation density or vegetation optical depth $(\tau)$ is a dimensionless parameter that can be interpreted as being directly proportional to vegetation water content (Jackson and O'Neill 1990; Jackson and Schmugge 1991) and was derived simultaneously with the LPRM according to analytical approach of Meesters et al. (2005).

Figure $5 \mathrm{~b}$ shows the spatial distribution of the vegetation density. The desert regions $(\tau<0.1)$ don't show a specific correlation and have a median value of $-0.08 \pm 0.5$. In sparse to moderate vegetated regions $(\tau=0.1-0.5)$ ERS and AMSR-E soil moisture compare well with a median value of $0.83 \pm 0.4$. For the more densely vegetated regions (i.e. $\tau=0.5-0.6$, and $\tau>0.6$ ), the correlation decreases to median values of $0.47 \pm 0.4$ to $0.33 \pm 0.4$, respectively. It is expected that the new satellite sensor onboard of the SMOS mission will obtain more reliable soil moisture values from these regions because L-band observations have a greater vegetation penetration.

The low correlation coefficients in the desert regions were due to both the low sensitivity of the dielectric constant of the soil on soil moisture when it is dry and the scattering volume anomaly. This affects the quality of both the ERS and AMSR-E soil moisture products but in different ways, resulting in low correlation values. In spite of these issues, both products reveal on average similar low soil moisture values in the desert regions. The decrease in correlation for the more vegetated regions can be addressed to the increasing contribution of vegetation on the microwave signal. Soil emission is attenuated by the vegetation and as the vegetation cover becomes denser the sensitivity of the microwave sensor to retrieve soil moisture information will subsequently decrease (i.e. Fig. 2).

In order to get a global overview of both products, a general statistical analysis was applied on 9 year historical ERS data. The period January 1992-December 2000 was selected, because for this period the ERS soil moisture product still had a full global coverage. For AMSR-E the analysis is applied to four years (January 2003 till December 2006) of soil moisture retrievals as derived from descending C-band overpasses. Even though the global statistics from these data sets represent different periods for each product, we do expect to find similar patterns.

In Fig. 6(a, b) the global average soil moisture values are presented. Both products show a similar distribution with low values in the deserts and semi arid regions and high values in the northern latitudes and dense vegetated regions. A few regions deviate. Australia is 
(a)

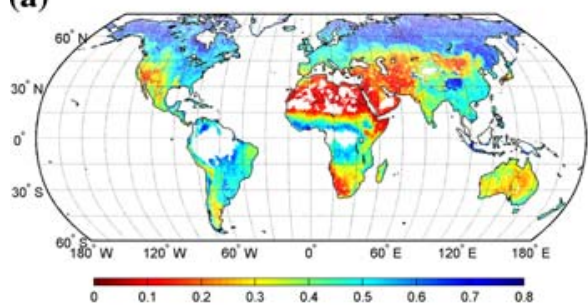

(c)

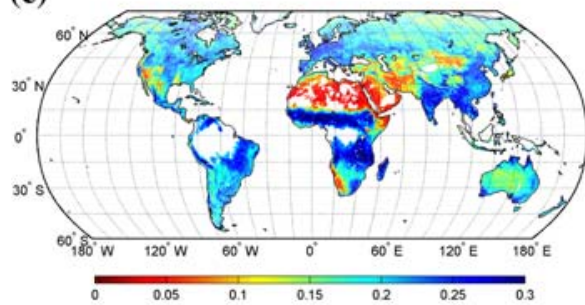

(e)

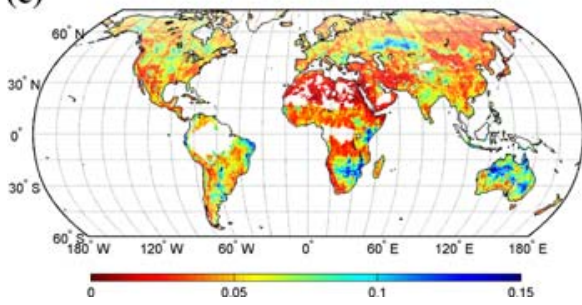

(b)

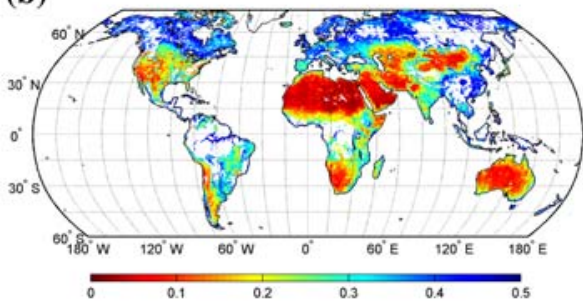

(d)

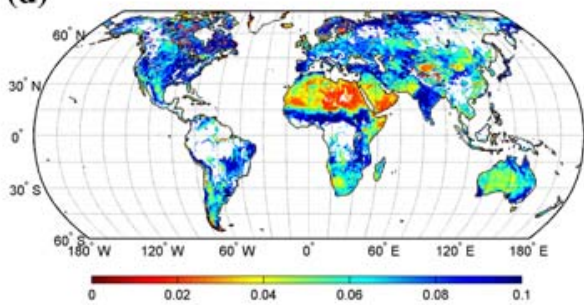

(f)

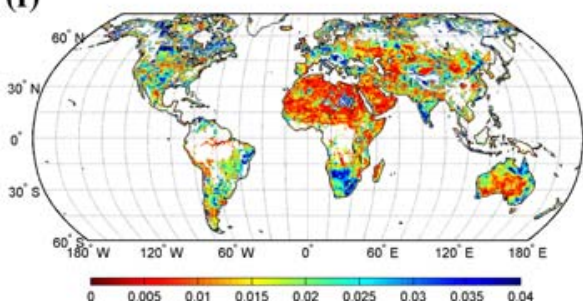

Fig. 6 General statistics of 9 years of ERS (a, c, and e; 1992-2000) and 4 years of AMSR-E C-band (b, d, and f; 2003-2006) soil moisture data. (a) and (b) represent the annual average soil moisture value of respectively ERS and AMSR-E, (c) and (d) the standard deviation, and (e) and (f) the inter annual standard deviation. Please note that ERS soil moisture is based on a relative quantity ranging between 0 (dry) and 1 (saturated) and AMSR-E soil moisture is based on volumetric units $\left(\mathrm{m}^{3} \mathrm{~m}^{-3}\right)$

for example less dry in the ERS data compared tot AMSR-E data. This is actually true because Australia is recently subject to frequent droughts, and many areas have been experiencing extraordinary drought conditions since 2000 (Liu et al. 2007). The AMSR-E average map of Australia was derived from these dry years. Other deviated regions can be found in China and the Kashmir region and are also due to dominant wet and/or dry years during the 2003-2006 period. The differences of these regions may also be caused by the effect of mountains. Mountainous regions can both affect the roughness and the incidence angle, resulting in deviating soil moisture values.

Figure 6(c, d) shows the standard deviation of both ERS and AMSR-E. The standard deviation is based on the daily observations and is an excellent descriptor of the average seasonal variation. Both products have a very high spatial correspondence with high seasonal dynamics in the Sahel region, India, Eastern part of North America, and Western Europe. The seasonal variation in Eastern part of North America is more outspoken in the ERS dataset. This is probably due to RFI problems in the AMSR-E dataset that ads to the natural standard deviation (Njoku et al. 2005). The AMSR-E dataset shows more seasonal variation in Eurasia, and in particular Turkey. The lack of seasonal variation in the ERS dataset in these regions might be related to the backscatter anomaly when the soil is very 
dry. Compared to AMSR-E soil moisture this anomaly will results in higher soil moisture values in the summertime and consequently in low standard deviation values.

Figure 6(e,f) describes the standard deviation of the average annual maps and is a good descriptor to distinguish inter annual variation. These inter annual images are somewhat comparable. However, it is important to realize that the analyses are applied for different years and that we should not expect a lot of similarities. Nevertheless, comparable strong variations are detected in Botswana, Eastern Australia, and Eastern Brazil. For all these regions it is known that large scale oceanic circulations like El Nino Southern Oscillation (ENSO), have a dominant effect on precipitation over land (Los et al. 2001). A recent study just revealed a strong relationship between ENSO and satellite derived soil moisture in Eastern Australia (Liu et al. 2007). These two maps show that similar relationships can be expected in both the ERS and AMSR-E dataset.

\section{Summary and Conclusions}

Within the scope of future soil moisture assessment with ESA's satellite mission of SMOS an evaluation study has been applied on two existing and public available global soil moisture products. ERS scatterometer surface wetness data was compared to the AMSR-E soil moisture data set.

The ERS scatterometer surface wetness data was developed by the Technical University of Vienna (Wagner et al. 1999a, b) and converted C-band backscatter measurements into soil moisture values. The AMSR-E soil moisture data set was developed by collaboration between NASA Goddard Space Flight Center and the Vrije Universiteit Amsterdam and used the Land Parameter Retrieval Model to extract soil moisture values from C-band passive microwave brightness temperatures. This study pointed out a strong similarity between both products in sparse to moderate vegetated regions with an average correlation coefficient of 0.83 .

In this vegetation regime it is very likely that the data sets are of high quality, because it is unexpected that the same errors are present in the data sets given the very different sensors and retrieval approaches.

Low correlations were found in densely vegetated areas and deserts with average correlation coefficient values of respectively -0.08 and 0.33 .

The lower values in the vegetated regions can be explained by the limited soil moisture retrieval capabilities over dense vegetation covers. Soil emission is attenuated by the canopy and tends to saturate the microwave signal with increasing vegetation density, resulting in a decreased sensor sensitivity to soil moisture variations. The upcoming launch of SMOS with L-band radiometry might be able to tackle this issue because compare to Cband, the L-band has a greater penetration of vegetation. It is therefore expected that SMOS will obtain higher quality soil moisture products in these regions. This is not entirely true for the derivation of soil moisture with L-band radar backscatter, because here appropriate filtering and calibration of surface roughness parameters are needed to derive reliable values (Walker et al. 2004).

Low correlations in the desert regions are due to the low variability of the signal. Also, artefacts which may possibly be due to volume scattering effects in very dry soils may even cause negative correlations between the scatterometer and radiometer measurements. The volume scattering in dry soils causes a higher backscatter under very dry conditions than under conditions when the sub-surface soil layers are somewhat wet. Nevertheless both datasets show low soil moisture values in these regions. 
At a global scale the spatial correspondence of both products is high and both products clearly distinguish similar regions with high seasonal and inter annual variations. We concluded that the quality of both products was comparable.

Based on several differences in limitations of each product (i.e. RFI in AMSR-E, some misinterpretation of ERS in desert regions) we think there is a significant potential to combine both products into one superior soil moisture data set. This will be a logical step forward in soil moisture research and might have a strong impact on the proposed future NASA mission Soil Moisture Active Passive (SMAP), a planned satellite system with both a scatterometer and a radiometer.

The questions of whether, where and how coarse resolution satellite data can be used at finer scales are important because, within the next few years, only coarse resolution $(25-50 \mathrm{~km})$ soil moisture data derived from spaceborne radiometer and scatterometer systems can be expected to be operationally available (Wagner et al. 2007a, b). Global soil moisture products are already available. For soil moisture retrieval at finer spatial scales, Synthetic Aperture Radar (SAR) may be used. However, scientific and technological breakthroughs are still needed for the operational use of SAR (Kerr 2007; Wagner et al. 2008).

Finally, it is envisaged that the above described methodologies will continue to provide global soil moisture products from various satellite sensors, including the satellites discussed in this paper. During the operation of SMOS these products will be available for initial soil moisture validation, especially for the semi-arid and moderate vegetated regions. Compared to the existing soil moisture methodologies, SMOS is expected to provide a more quantitative soil moisture product, which rules out a quantitative validation. However, the temporal and spatial characteristics of the described global soil moisture sets can be valuable for SMOS soil moisture validation.

Open Access This article is distributed under the terms of the Creative Commons Attribution Noncommercial License which permits any noncommercial use, distribution, and reproduction in any medium, provided the original author(s) and source are credited.

\section{References}

Ahmed NU (1995) Estimating soil moisture from 6.6 GHz dual polarization, and/or satellite derived vegetation index. Int J Remote Sens 16:687-708. doi:10.1080/01431169508954434

Ashcroft P, Wentz F (2003) AMSR-E/Aqua L2A global swath spatially-resampled brightness temperatures (Tb) V001, September to October 2003. National Snow and Ice Data Center, Boulder, CO, USA. Digital media (Updated daily)

Attema EPW, Ulaby FT (1978) Vegetation modeled as water cloud. Radio Sci 13:357-364. doi:10.1029/ RS013i002p00357

Bartalis Z, Scipal K, Wagner W (2006) Azimuthal anisotropy of scatterometer measurements over land. IEEE Trans Geosci Remote Sens 44:2083-2092. doi:10.1109/TGRS.2006.872084

Choi M, Jacobs JM (2008) Temporal variability corrections for advanced microwave radiometer E (AMSRE) surface soil moisture: case study in Little River Region, Georgia. U.S. Sensors 8:2617-2627

Choudhury BJ, Schmugge TJ, Chang ATC, Newton NR (1979) Effect of surface roughness on the microwave emission of soils. J Geophys Res 84:5699-5705. doi:10.1029/JC084iC09p05699

Crapolicchio R, Lecomte P (2005) The ERS-2 scatterometer mission: events and long-loop instrument and data performances assessment. In: Proceedings of the 2004 ENVISAT \& ERS Symposium, 6-10 September 2004, Salzburg, Austria, European Space Agency, SP-572, CDROM

Crow WT, Zhan X (2007) Continental-scale evaluation of remotely sensed soil moisture products. IEEE Geosci Remote Sens Lett 4:451-455. doi:10.1109/LGRS.2007.896533

De Jeu RAM (2003) Retrieval of land surface parameters using passive microwave remote sensing. PhD Dissertation, VU University Amsterdam, 122 pp 
De Jeu RAM, Owe M (2003) Further validation of a new methodology for surface moisture and vegetation optical depth retrieval. Int J Remote Sens 24:4559-4578. doi:10.1080/0143116031000095934

Dirmeyer PA, Guo ZG, Gao X (2004) Comparison, validation, and transferability of eight multiyear global soil wetness products. J Hydrometeorol 5:1011-1033. doi:10.1175/JHM-388.1

Dobson M, Ulaby FT, Hallikainen MT, El-Rayes MA (1985) Microwave dielectric behavior on wet soils, II dielectric mixing models. IEEE Trans Geosci Remote Sens 23:35-46. doi:10.1109/TGRS.1985.289498

Draper CS, Walker JP, Steinle PJ, De Jeu RAM, Holmes TRH (2007) Remotely sensed soil moisture over Australia from AMSR-E. In: Proceedings MODSIM 2007, Christchurch

Drusch M, Wood EF, Gao H, Thiele A (2004) Soil moisture retrieval during the Southern Great Plains Hydrology Experiment 1999: a comparison between experimental remote sensing data and operational products. Water Resour Res 40:W02504. doi:10.1029/2003WR002441

Eagleman JR, Ulaby FT (1975) Remote sensing of soil moisture by SKYLAB radiometer and scatterometer sensors. J Astronaut Sci 23:147-159

Fung AK (1979) Scattering from a vegetation layer. IEEE Trans Geosci Electron 17:1-6. doi:10.1109/ TGE.1979.294601

Fung AK, Li ZQ, Chen KS (1992) Backscattering from a randomly rough dielectric surface. IEEE Trans Geosci Remote Sens 30:356-369. doi:10.1109/36.134085

Gruhier C, De Rosnay P, Kerr Y, Mougin E, Ceschia E, Calvet JC (2008) Evaluation of AMSR-E soil moisture product based on ground measurements over temperate and semi arid regions. Geophys Res Lett 34. doi:10.1029/2008GL033330

Hipp JE (1974) Soil electromagnetic parameters as functions of frequency, soil density, and soil moisture. In: Proceedings of the IEEE 62:98-103

Imaoka K, Fujimoto Y, Arai Y, Shibata A, Morokuma S, Sasaki Y (2006) Radio-frequency interference signals in the AMSR and aircraft C-band measurements. IEEE International Conference on Geoscience and Remote Sensing Symposium, 2006. IGARSS 2006, pp 2297-2300. doi:10.1109/IGARSS.2006.594

Jackson TJ, O'Neill PE (1990) Attenuation of soil microwave emission by corn and soybeans at 1.4 and 5 GHz. IEEE Trans Geosci Remote Sens 28:978-980. doi:10.1109/36.58989

Jackson TJ, Schmugge TJ (1991) Vegetation effects on the microwave emission from soils. Remote Sens Environ 36:203-212. doi:10.1016/0034-4257(91)90057-D

Jackson TJ, Schmugge TJ, Wang JR (1982) Passive microwave sensing of soil moisture under vegetation canopies. Water Resour Res 18:1137-1142. doi:10.1029/WR018i004p01137

Jackson TJ, Bras R, England A et al (1999) Soil Moisture Research Mission (EX-4), Report NASA Post2002 Land Surface Hydrology Planning Workshop, 28 pp

Jackson TJ, Cosh MH, Bindlish R, Du J (2007) Validation of AMSR-E soil moisture algorithms with ground based networks. Proceedings of the international geoscience and remote sensing symposium

Kerr YH (2007) Soil moisture from space: where are we? Hydrogeol J 15:117-120. doi:10.1007/ s10040-006-0095-3

Kerr YH, Waldteufel P, Wigneron JP, Martuzzi JM, Font J, Berger M (2001) Soil moisture retrieval from space: the soil moisture and ocean salinity (SMOS) mission. IEEE Trans Geosci Remote Sens 39:1729-1735. doi:10.1109/36.942551

Kirdiashev KP, Chukhlantsev AA, Shutko AM (1979) Microwave radiation of the Earth's surface in the presence of vegetation cover. Radio Eng Electron Phys 24:256-264 (English Trans)

Lecomte P (1998) The ERS Scatterometer instrument and the on-ground processing of its data. In: Proceedings of workshop on emerging scatterometer applications: from research to operations, Noordwijk, The Netherlands, 5-7 October 1998, European Space Agency, Special Publication 424: 241-260

Leese J, Jackson T, Pitman A, Dirmeyer A (2001) Meeting summary, GEWEX/BAHC international workshop on soil moisture monitoring, analysis, and prediction for hydrometeorological and hydroclimatological applications. Bull Am Met Soc 82:1423-1430

Li L, Njoku EG, Im E, Chang PS, Germaine K (2004) A preliminary survey of radio-frequency interference over the U.S. in Aqua AMSR-E data. IEEE Trans Geosci Remote Sens 42:380-390. doi:10.1109/ TGRS.2003.817195

Liebe HJ (2004) MPM - an atmospheric millimeter-wave propagation model. Int J Infrared Millim Waves 10:631-650. doi:10.1007/BF01009565

Liu Y, De Jeu RAM, Van Dijk AIJM, Owe M (2007) TRMM-TMI satellite observed soil moisture and vegetation density (1998-2005) show strong connection with El Nino in eastern Australia. Geophys Res Lett 34. doi:10.1029/2007GL030311

Los SO, Collatz GJ, Bounoua L, Sellers PJ, Tucker CJ (2001) Global interannual variations in sea surface temperature and land surface vegetation, air temperature and precipitation. J Clim 14:1535-1549. doi $: 10.1175 / 1520-0442(2001) 014<1535:$ GIVISS $>2.0 . C O ; 2$ 
McLaughlin DJ, McIntosh RE, Pazmany A, Hevizi L, Boltniew E (1991) A C-band scatterometer for remote sensing the air-sea interface. IEEE Trans Geosci Remote Sens 29:260-267. doi:10.1109/36.73667

Meesters AGCA, De Jeu RAM, Owe M (2005) Analytical derivation of the vegetation optical depth from the microwave polarization difference index. IEEE Geosci Remote Sens Lett 2:121-123. doi:10.1109/ LGRS.2005.843983

Mironov VL, Dobson C, Kaupp VH, Komarov VA, Kleshchenko VN (2004) Generalized refractive mixing dielectric model for moist soils. IEEE Trans Geosci Remote Sens 42:773-785. doi:10.1109/TGRS. 2003.823288

Mo T, Choudhury BJ, Schmugge TJ, Wang JR, Jackson TJ (1982) A model for microwave emission from vegetation-covered fields. J Geophys Res 87:11229-11237. doi:10.1029/JC087iC13p11229

Njoku EG, Kong JA (1977) Theory for passive microwave remote sensing of near-surface soil moisture. J Geophys Res 82:3108-3118. doi:10.1029/JB082i020p03108

Njoku EG, Li L (1999) Retrieval of land surface parameters using passive microwave measurements at 618 GHz. IEEE Trans Geosci Remote Sens 37:79-93. doi:10.1109/36.739125

Njoku EG, Jackson T, Lakshmi V, Chan T, Nghiem SV (2003) Soil moisture retrieval from AMSR-E. IEEE Trans Geosci Remote Sens 41:215-229. doi:10.1109/TGRS.2002.808243

Njoku EG, Ashcroft P, Chan TK, Li L (2005) Global survey and statistics of radio-frequency interference in AMSR-E land observations. IEEE Trans Geosci Remote Sens 43:938-947. doi:10.1109/TGRS. 2004.837507

NSIDC (2006) Data products and services. National Snow and Ice Data Center, Boulder

Oh Y, Sarabandi K, Ulaby FT (1992) An empirical model and an inversion technique for radar scattering from bare soil surfaces. IEEE Trans Geosci Remote Sens 30:370-381. doi:10.1109/36.134086

Owe M, De Jeu RAM, Walker JP (2001) A methodology for surface soil moisture and vegetation optical depth retrieval using the microwave polarization difference index. IEEE Trans Geosci Remote Sens 39:1643-1654. doi:10.1109/36.942542

Owe M, De Jeu RAM, Holmes TRH (2008) Multi-sensor historical climatology of satellite-derived global land surface moisture. J Geophys Res 113. doi:10.1029/2007JF000769

Parajka J, Naeimi V, Blöschl G, Wagner W, Merz R, Scipal K (2006) Assimilating scatterometer soil moisture data into conceptual hydrologic models at the regional scale. Hydrol Earth Syst Sci 10:353368

Pellarin T, Wigneron JP, Calvet JC, Waldteufel P (2003) Global soil moisture retrieval from a synthetic Lband brightness temperature dataset. J Geophys Res 108:9-19. doi:10.1029/2002JD003086

Pellarin T, Calvet JC, Wagner W (2006) Evaluation of ERS scatterometer soil moisture products over a halfdegree region in southwestern France. Geophys Res Lett 33. doi:10.1029/2006GL027231

Peplenski N, Ulaby F, Dobson M (1995) Dielectric properties of soils in the 0.3-1.3 GHz range. IEEE Trans Geosci Remote Sens 33:803-807. doi:10.1109/36.387598

Pulliainen JT, Hallikainen MT, Grandell J (1999) HUT snow emission model and its applicability to snow water equivalent retrieval. IEEE Trans Geosci Remote Sens 37:1378-1390. doi:10.1109/36.763302

Remy F, Ledroit M, Minster JF (1992) Katabatic wind intensity and direction over antartica derived from scatterometer data. Geophys Res Lett 19:1021-1024. doi:10.1029/92GL00970

Rüdiger C, Calver JC, Gruhier C, Holmes TRH, De Jeu RAM, Wagner WW (2008) An intercomparison of ERS-Scat and AMSR-E soil moisture observations with model simulations over France. J Hydrometeorol (submitted)

Saleh K, Wigneron JP, De Rosnay P, Calvet JC, Escorihuela MJ, Kerr Y et al (2006) Impact of rain interception by vegetation and much on the L-band emission of natural grass. Remote Sens Environ 101:127-139. doi:10.1016/j.rse.2005.12.004

Schanda E (1986) Physical fundamentals of remote sensing. Springer Verlag, Berlin, 187 pp

Schanda E (1987) On the contribution of volume scattering to the microwave backscattered signal from wet snow and wet soil. Int J Remote Sens 8:1489-1500. doi:10.1080/01431168708954791

Schmugge TJ (1985) Remote sensing of soil moisture. In: Anderson M, Burt T (eds) Hydrological forecasting. Wiley, New York

Schmugge TJ, Neil O, Wang PE Jr (1986) Passive microwave soil moisture research. IEEE Trans Geosci Remote Sens 24:12-22. doi:10.1109/TGRS.1986.289584

Schneeberger K, Schwank M, Stamm C, De Rosnay P, Mätzler C, Flühler H (2004) Topsoil structure influencing soil water retrieval by microwave radiometry. Vadose Zone J 3:1169-1179

Schwank M, Mätzler C, Guglielmetti M, Flühler H (2005) L-Band radiometer measurements of soil water under growing clover grass. IEEE Trans Geosci Remote Sens 43:2225-2237. doi:10.1109/TGRS. 2005.855135

Stephen H, Long DG (2005) Microwave backscatter modeling of Erg surfaces in the Sahara desert. IEEE Trans Geosci Remote Sens 43:238-247. doi:10.1109/TGRS.2004.840646 
Ulaby FT (1974) Radar measurement of soil moisture content. IEEE Trans Antennas Propag 22:257-265. doi:10.1109/TAP.1974.1140761

Ulaby FT, Moore RK, Fung AK (1981) Microwave remote sensing: active and passive, vol I. Microwave remote sensing fundamentals and radiometry, Artech House, Noorwood

Ulaby FT, Moore RK, Fung AK (1982) Microwave remote sensing: active and passive, vol II. Radar remote sensing and surface scattering and emission theory, Artech House, Noorwood

Van de Griend AA, Owe M (1994) Microwave vegetation optical depth and inverse modelling of soil emissivity using Nimbus/SMMR satellite observations. Meteorol Atmos Phys 54:225-239. doi: 10.1007/BF01030062

Wagner W, Lemoine G, Borgeaud M, Rott H (1999a) A study of vegetation cover effects on ERS scatterometer data. IEEE Trans Geosci Remote Sens 37:938-948. doi:10.1109/36.752212

Wagner W, Lemoine G, Rott H (1999b) A method for estimating soil moisture from ERS scatterometer and soil data. Remote Sens Environ 70:191-207. doi:10.1016/S0034-4257(99)00036-X

Wagner W, Scipal K, Pathe C, Gerten D, Lucht W, Rudolf B (2003) Evaluation of the agreement between the first global remotely sensed soil moisture data with model and precipitation data. J Geophys Res 108. doi:10.1029/2003JD003663

Wagner W, Blöschl G, Pampaloni P, Calvet JC, Bizzarri B, Wigneron JP et al (2007a) Operational readiness of microwave remote sensing of soil moisture for hydrologic applications. Nord Hydrol 38:1-20. doi: 10.2166/nh.2007.029

Wagner W, Naeimi V, Scipal K, De Jeu R, Fernandez JM (2007b) Soil moisture from operational meteorological satellites. Hydrogeology 15:121-131. doi:10.1007/s10040-006-0104-6

Wagner W, Pathe C, Doubkova M, Sabel D, Bartsch A, Hasenauer S et al (2008) Temporal stability of soil moisture and radar backscatter observed by the advanced synthetic aperture radar (ASAR). Sensors 8:1175-1197

Walker JP, Houser PR, Willgoose GR (2004) Active microwave remote sensing for soil moisture measurement: a field evaluation using ERS-2. Hydrol Process 18:1975-1997. doi:10.1002/hyp.1343

Wang JR, Choudhury BJ (1981) Remote sensing of soil moisture content over bare field at $1.4 \mathrm{GHz}$ frequency. J Geophys Res 86:5277-5282. doi:10.1029/JC086iC06p05277

Wang JR, Schmugge TJ (1980) An empirical model for the complex dielectric permittivity of soil as a function of water content. IEEE Trans Geosci Remote Sens 18:288-295. doi:10.1109/TGRS.1980. 350304

Wegmuller U, Maetzler C, Njoku EG (1995) Canopy opacity models. In: Choudhury BJ et al (eds) Passive microwave remote sensing of land-atmosphere interactions. VSP International Science Publications, Utrecht, pp 375-387

Wigneron JP, Chanzy A, Calvet JC, Bruguier N (1995) A simple algorithm to retrieve soil moisture and vegetation biomass using passive microwave measurements over crop fields. Remote Sens Environ 51:331-341. doi:10.1016/0034-4257(94)00081-W

Wigneron JP, Laguerre L, Kerr YH (2001) A simple parameterization of the L-band microwave emission from rough agricultural soils. IEEE Trans Geosci Remote Sens 39:1697-1707. doi:10.1109/36.942548

Wilheit TTJ (1975) Radiative transfer in a plane stratified dielectric. Technical Report X-911-75-66, NASA/ GSFC

Young J, Moore R (1977) Active microwave measurement from space of sea-surface winds. IEEE J Ocean Eng 2:309-317. doi:10.1109/JOE.1977.1145357 